\title{
Validation of a symptom-score questionnaire and long- term results of endoscopic dacryocystorhinostomy*
}

\author{
Elina Penttilä', Grigori Smirnov ${ }^{1,2}$, Juha Seppä', Henri Tuomilehto ${ }^{1,2}$, \\ Hannu Kokki ${ }^{3}$ \\ ' Department of Otorhinolaryngology, Kuopio University Hospital, and Institute of Clinical Medicine, University of \\ Eastern Finland, Finland \\ 2 Oivauni Sleep Clinic, Kuopio, Finland \\ ${ }^{3}$ Department of Anesthesia and Operative Services, Kuopio University Hospital, and Institute of Clinical Medicine, \\ University of Eastern Finland, Finland
}

Rhinology 52: 84-89, 2014

DOI:10.4193/Rhino13.041

Published online: November 3,2013

*Received for publication:

April 15, 2013

Accepted: August 24, 2013

\begin{abstract}
Background: Endoscopic dacryocystorhinostomy (EN-DCR) is a commonly used procedure in the treatment of nasolacrimal duct obstruction (NLDO). However, there is no generally accepted disease-specific questionnaire for assessing outcomes.

Methodology: We conducted a prospective study to initially validate a Nasolacrimal Duct Obstruction Symptom Score questionnaire (NLDO-SS) and to evaluate the long-term success of EN-DCR procedures. Seventy-six patients (86 eyes) were evaluated in follow-up visits at 1-8 years after EN-DCR. The patients completed the NLDO-SS questionnaire twice, first, at home and, second, after receiving information from the otorhinolaryngologist, during the visit. The surgical outcome was considered successful if the irrigation succeeded and if the patient symptoms were relieved as assessed with the NLDO-SS.
\end{abstract}

Results: The diagnostic accuracy of the NLDO-SS was $84 \%$, sensitivity $82 \%$, specificity $85 \%$, positive predictive value $58 \%$, negative predictive value $95 \%$, odds ratio 26 , risk ratio 11 and usefulness index 0.55 . Cronbach's alpha was 0.85 , and the test-retest reliability coefficient was 0.87 . The long-term success rate after EN-DCR was $79 \%$.

Conclusion: The NLDO-SS iss a feasible clinical tool in assessing the success of EN-DCR. The success rate was found to decrease EN-DCR at long-term follow-up.

Key words: dacryocystitis, dacryocystorhinostomy, epiphora, long-term follow-up, nasolacrimal duct obstruction, symptom score questionnaire, validation

\section{Introduction}

Nasolacrimal duct obstruction (NLDO) is a common condition in elderly patients ${ }^{(1)}$, and it may significantly affect their quality of life and well-being. When treating NLDO, endoscopic dacryocystorhinostomy (EN-DCR) is a commonly used surgical technique. The purpose of this procedure is to bypass the obstruction by creating a rhinostoma between the lacrimal sac and the nasal cavity.

Patient satisfaction regarding symptom relief and improvement in quality of life is the predominant consideration when determining the success of surgical interventions. The Glasgow
Benefit Inventory $(\mathrm{GBI})$ is a validated and generally accepted measure developed for otorhinolaryngological interventions ${ }^{(2)}$. $\mathrm{GBI}$ is a generic tool used to assess post-intervention well-being and does not itself provide information on surgical outcomes. Another limitation of the GBI in assessing outcomes of EN-DCR is that it is not disease-specific and ocular symptoms are not included. In assessing the overall success of lacrimal surgery, the anatomical and physiological patency must also be considered. Consequently, there is a clinical need for a generally accepted and validated disease-specific instrument that could be used for the assessment of symptoms and subjective outcome. To improve the evaluation, we have developed a Nasolacrimal 
Duct Obstruction Symptom Score (NLDO-SS) questionnaire with items focused on the common ocular and nasal symptoms of NLDO. Our pilot study indicated that the NLDO-SS provides more information than the GBI alone, and that EN-DCR resulted in a significant reduction in all of the symptom scores in followup of 6 months ${ }^{(3)}$.

Although the success of primary EN-DCR has been reported to be high and to vary between $74 \%$ and $94 \%{ }^{(4)}$, obstruction of the rhinostoma can appear years after the operation ${ }^{(5)}$. However, only a few prospective studies have investigated the long-term success rates of EN-DCR ${ }^{(6,7)}$.

The aims of this study were to initially validate the NLDO-SS and to evaluate the long-term success rate of surgery in this prospective study population.

\section{Materials and methods}

\section{Study design}

This study is part of our prospective EN-DCR trial. Recruitment began in 2004, and the participants were recruited consecutively from the adult NLDO patients referred to the outpatient clinic of the Department of Otorhinolaryngology at Kuopio University Hospital in Kuopio, Finland. The patients were eligible for participation if they were adults (age 18 years or older), if their American Society of Anesthesiologist physical status was $1-3$, and if they were scheduled for primary or revision lacrimal pathway surgery due to NLDO or recurrent infection. In the preoperative assessment, the diagnosis was confirmed from the clinical history i.e. symptoms of the patients and with the irrigation test. Patients were excluded if they had a pre-saccal obstruction; had a malignancy in the paranasal sinuses, nasal cavity or lacrimal pathway; had a mental disability; or were pregnant or breast feeding. If no contraindications existed, all EN-DCRs were performed under standardised endotracheal general anaesthesia. The standardised powered instrumentation and postoperative care were as we have previously described ${ }^{(8)}$.

We sent an invitation for an additional study visit to patients who had been operated on at least one year earlier at the Department of Otorhinolaryngology, Kuopio University Hospital. The patients were provided with oral and written information on the trial protocol, and they provided written consent. The study was approved by the Research Ethics Committee of the Hospital District of Northern Savo, Kuopio, Finland.

\section{Patients}

The flow chart is presented in Figure 1. Altogether, 116 adult patients had undergone primary or revision EN-DCR between January 2004 and September 2010. A total of 105 consecutive patients were asked to participate, and $76(72 \%)$ agreed. Ten of these participants had had bilateral surgery; therefore, outcomes of 86 procedures were assessed. The demographics of the patients are presented in Table 1.

\section{Clinical examination}

Clinical examinations of the patients were performed by an experienced rhinologist between May 2011 and October 2011. Irrigation of the lacrimal sac was performed to check the patency of the nasolacrimal pathway. All patients underwent nasoendoscopy, and the findings in the nasal cavity were evaluated using the Lund-MacKay staging system ${ }^{(9)}$. The surgical outcome was considered successful (i) if the saline solution reached the nose easily during the lacrimal sac irrigation and (ii) if the patients symptoms were relieved.

\section{Questionnaire development}

The item areas for the NLDO-SS were developed by an expert panel of individuals with long experience in the treatment of NLDO, and questions were based on the literature. In the NLDOSS, the symptoms are graded based on a Likert scaling model using an 11-point numeric rating scale $(0=$ no symptoms, $10=$ worst imaginable symptom). The total score for the NLDO-SS ranges from 0 to 70 points. The NLDO-SS questionnaire comprises five items that focus on the common ocular symptoms (tearing, discharge from the eye, swelling around the eye, pain around the eye and change in visual acuity) and two items relating to the conditions in the nasal cavity (blockage and discharge). Because nasal pathology may underlie some of the NLDO ${ }^{(10)}$ and because it also plays an important role in the failure of the surgery ${ }^{(11,12)}$, nasal symptoms were included in the survey. In our initial questionnaire, an additional question concerning the ge-

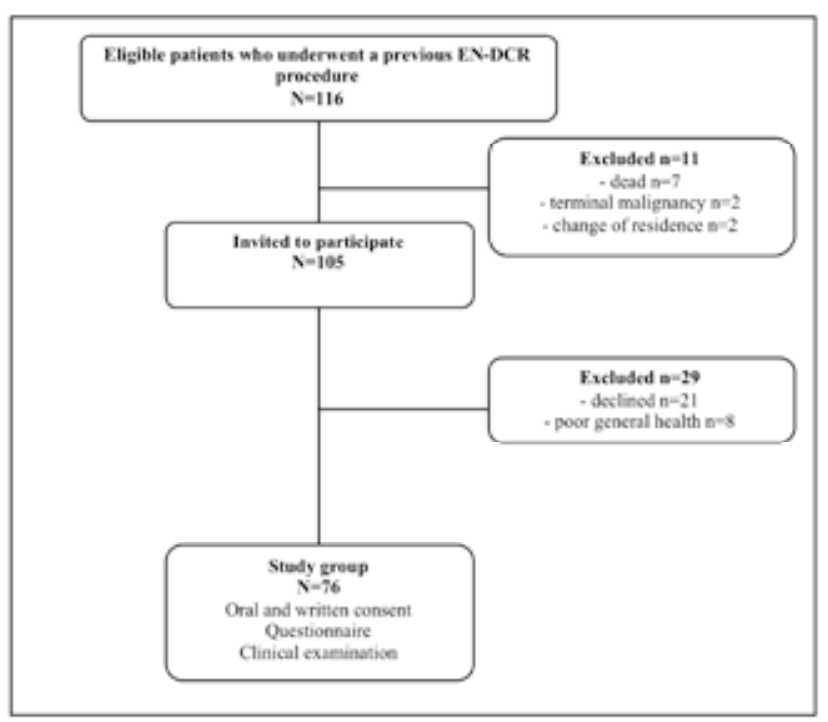

Figure 1. Flow chart. 
Table 1. Baseline demographics of the study group. Data are the number of cases or the mean (SD) and median [minimum-maximum].

\begin{tabular}{|c|c|c|c|}
\hline \multicolumn{3}{|l|}{ Variable } & $n=76$ \\
\hline \multicolumn{2}{|l|}{ Sex } & $\begin{array}{l}\text { Male } \\
\text { Female }\end{array}$ & $\begin{array}{l}16 \\
60\end{array}$ \\
\hline \multicolumn{2}{|c|}{ Age (yr) at time of operation } & & $\begin{array}{c}62(12) \\
63[29-89]\end{array}$ \\
\hline \multicolumn{2}{|c|}{ Follow-up time (yr) } & & $\begin{array}{c}4(2) \\
4[1-8]\end{array}$ \\
\hline \multirow[t]{4}{*}{ Procedures* } & $\mathrm{n}=86$ & & \\
\hline & Laterality & $\begin{array}{l}\text { Right } \\
\text { Left }\end{array}$ & $\begin{array}{l}42 \\
44\end{array}$ \\
\hline & Diagnosis & $\begin{array}{l}\text { Dacryostenosis } \\
\text { Chronic or recurrent } \\
\text { dacryocystitis }\end{array}$ & $\begin{array}{l}57 \\
29\end{array}$ \\
\hline & Surgery & $\begin{array}{l}\text { Primary without } \\
\text { stents } \\
\text { Primary with stents } \\
\text { Revision without } \\
\text { Mitomycin-C } \\
\text { Revision with } \\
\text { Mitomycin-C }\end{array}$ & $\begin{array}{l}53 \\
11 \\
12 \\
10\end{array}$ \\
\hline
\end{tabular}

* 10 patients underwent a bilateral operation

neral condition of the patient was included. However, because of the low specificity of this additional question, we excluded it from the final version. In the present study, the NLDO-SS was completed twice by the patients: first, independently at home and, second, after receiving information from the otorhinolaryngologist, during the visit. If answers to the same question differed by only \pm 1 point, they were categorised as equivalent.

\section{Questionnaire validation}

The validity of the questionnaire was evaluated using several different methods. The main outcome measure when testing the quality and usefulness of the NLDO-SS was the diagnostic accuracy (the percentage of correctly diagnosed patients). We also calculated its sensitivity (the test's ability to identify obstructed patients) and specificity (the test's ability to identify cured patients), its positive predictive value (the percentage of the patients with obstruction who were correctly diagnosed), and negative predictive value (the percentage of cured patients who were correctly diagnosed). Diagnostic accuracy was calculated as a $+d / a+b+c+d$, sensitivity as a / $a+c$, specificity as $d / b$ $+d$, positive predictive value as $a / a+b$, and negative predictive value as $d / c+d$, where a denotes true obstruction (true positive), $d$ denotes true success (true negative), b denotes high scores with success (false positive), and c denotes low scores in cured patients (false negative). The odds ratio (OR) was calculated as $(\mathrm{a} \times \mathrm{d}) /(\mathrm{c} \times \mathrm{b})$, the risk ratio (RR) as $[\mathrm{a} /(\mathrm{a}+\mathrm{b})] /[\mathrm{c} / \mathrm{c}$ $+d)$, and the usefulness index (UI) as sensitivity $\times$ [sensitivity (1-specificity)]. In addition, to evaluate the reliability, Cronbach's alpha was calculated. To further assess the internal consistency, correlations between single variables and the total scores were calculated for each patient. The test-retest reliability and the stability of the answers were evaluated by comparing the two sets of scores (initially filled-in independently at home and then again during the follow-up visit).

\section{Statistical methods}

Patient characteristics and variables analysed using the Statistical Package for Social Sciences (SPSS software version 18 for Windows, SPSS Inc., Chicago, USA). Correlations between nonparametric variables were tested using Spearman's rho. Differences between groups in categorical variables were assessed using Pearson's Chi-Squared test and Fisher's exact test. The distributions of ordinal variable data that were not normally distributed were compared using nonparametric tests. The Mann-Whitney $U$ test was used for comparing two independent samples, and McNemar's test was used for related samples. The differences were regarded statistically significant if a two-sided $P$-value was less than 0.05. Data are expressed as the number of cases, the mean \pm the standard deviation (SD) or median [minimum - maximum] as appropriate.

\section{Results}

The diagnostic accuracy of the NLDO-SS was $84 \%$, and the negative predictive value was $95 \%$, with a cut-off point $\geq 21 / 70$ for failed and $\leq 10 / 70$ for successful. Cronbach's alpha was 0.85 , and the total score with these cut-off points provided an OR of 26 , RR of 11.5 and a UI of 0.55 . Details of the diagnostic performance of the questionnaire are shown in Table 2 . The interpretability of the NLDO-SS was assessed by comparing the scores between the successes and failures (Table 3). An analysis of the symptom scores showed that eye symptoms performed better than nasal symptoms. There was no difference in nasal symptoms between the successful and failed patients. However, the total score differentiated the successes from the failures. When comparing the questionnaires completed at home with those completed during the visit, the test-retest reliability showed a high correlation between every variable, and the internal consistency of the questions was also high (Table 4).

For single variables with the cut-off points of $\leq 3 / 10$ for successes and $\geq 4 / 10$ for failures, the most significant predictors of outcomes were tearing $(\mathrm{OR}=46, \mathrm{RR}=24, \mathrm{UI}=0.64)$ and discharge $(\mathrm{OR}=92, \mathrm{RR}=24, \mathrm{UI}=0.70)$. The five other variables did not perform as well: swelling around the eye $(\mathrm{OR}=8.5, \mathrm{RR}=4.1, \mathrm{UI}=$ $0.14)$, pain around the eye $(\mathrm{OR}=6.5, \mathrm{RR}=3.4, \mathrm{UI}=0.07)$, change 
Table 2. Diagnostic performance of the Nasolacrimal Duct Symptom Score (NLDO-SS) questionnaire. Data are percentages (number of patients).

\begin{tabular}{|c|c|c|c|c|c|c|c|c|}
\hline Parameter & Total scores* & Tearing** & Discharge** & $\begin{array}{c}\text { Swelling } \\
\text { around the } \\
\text { eye }^{* *}\end{array}$ & $\begin{array}{l}\text { Pain around } \\
\text { the eye }\end{array}$ & $\begin{array}{c}\text { Change in } \\
\text { visual } \\
\text { acuity** }\end{array}$ & $\begin{array}{c}\text { Nose } \\
\text { blockage }^{* *}\end{array}$ & $\begin{array}{l}\text { Nasal cavity } \\
\text { discharge }^{* *}\end{array}$ \\
\hline $\begin{array}{l}\text { Diagnostic } \\
\text { accuracy }\end{array}$ & $\begin{array}{c}84 \% \\
(56+14 / 83)\end{array}$ & $\begin{array}{c}78 \% \\
(49+16 / 83)\end{array}$ & $\begin{array}{c}92 \% \\
(61+15 / 83)\end{array}$ & $\begin{array}{c}82 \% \\
(61+7 / 83)\end{array}$ & $\begin{array}{c}81 \% \\
(62+5 / 83)\end{array}$ & $\begin{array}{c}82 \% \\
(9+59 / 83)\end{array}$ & $\begin{array}{c}66 \% \\
(3+52 / 83)\end{array}$ & $\begin{array}{c}73 \% \\
(8+53 / 83)\end{array}$ \\
\hline Sensitivity & $\begin{array}{c}82 \% \\
(14 / 17)\end{array}$ & $\begin{array}{c}94 \% \\
(16 / 17)\end{array}$ & $\begin{array}{c}88 \% \\
(15 / 17)\end{array}$ & $\begin{array}{c}41 \% \\
(7 / 17)\end{array}$ & $\begin{array}{c}29 \% \\
(5 / 17)\end{array}$ & $\begin{array}{c}53 \% \\
(9 / 17)\end{array}$ & $\begin{array}{c}18 \% \\
(3 / 17)\end{array}$ & $\begin{array}{c}47 \% \\
(8 / 17)\end{array}$ \\
\hline Specificity & $\begin{array}{c}85 \% \\
(56 / 66)\end{array}$ & $\begin{array}{c}74 \% \\
(49 / 66)\end{array}$ & $\begin{array}{c}92 \% \\
(61 / 66)\end{array}$ & $\begin{array}{c}92 \% \\
(61 / 66)\end{array}$ & $\begin{array}{c}94 \% \\
(62 / 66)\end{array}$ & $\begin{array}{c}89 \% \\
(59 / 66)\end{array}$ & $\begin{array}{c}79 \% \\
(52 / 66)\end{array}$ & $\begin{array}{c}80 \% \\
(53 / 66)\end{array}$ \\
\hline $\begin{array}{l}\text { Positive pre- } \\
\text { dictive value }\end{array}$ & $\begin{array}{c}58 \% \\
(14 / 14+10)\end{array}$ & $\begin{array}{c}48 \% \\
(16 / 16+17)\end{array}$ & $\begin{array}{c}75 \% \\
(15 / 15+5)\end{array}$ & $\begin{array}{c}58 \% \\
(7 / 9+5)\end{array}$ & $\begin{array}{c}56 \% \\
(5 / 5+4)\end{array}$ & $\begin{array}{c}56 \% \\
(9 / 9+7)\end{array}$ & $\begin{array}{c}18 \% \\
(3 / 3+14)\end{array}$ & $\begin{array}{c}38 \% \\
(8 / 8+13)\end{array}$ \\
\hline $\begin{array}{l}\text { Negative pre- } \\
\text { dictive value }\end{array}$ & $\begin{array}{c}95 \% \\
(56 / 56+3)\end{array}$ & $\begin{array}{c}98 \% \\
(49 / 50)\end{array}$ & $97 \%(61 / 61+2)$ & $\begin{array}{c}86 \% \\
(61 / 61+10)\end{array}$ & $\begin{array}{c}84 \% \\
(62 / 62+12)\end{array}$ & $\begin{array}{c}88 \% \\
(59 / 59+8)\end{array}$ & $\begin{array}{c}79 \% \\
(52 / 52+14)\end{array}$ & $\begin{array}{c}85 \% \\
(53 / 53+9)\end{array}$ \\
\hline
\end{tabular}

* For success if NLDO-SS $\leq 10 / 70$ and for failure if NLDO-SS $\geq 21 / 70$

** For success if a single parameter $\leq 3 / 10$ and for failure if a single parameter $\geq 4 / 10$

Table 3. Scores of the Nasolacrimal Duct Obstruction Symptom Score (NLDO-SS) questionnaire completed by the patients at home using an 11-point Numeric Rating Scale $(0=$ no symptom, $10=$ worst imaginable symptom). Data are presented as the mean (SD) and median [minimummaximum].

\begin{tabular}{|c|c|c|c|}
\hline Variable & $\begin{array}{c}\text { Successes } \\
n=68\end{array}$ & $\begin{array}{c}\text { Failures } \\
n=18\end{array}$ & p-value \\
\hline Tearing & $\begin{array}{c}2(2) \\
2[0-8]\end{array}$ & $\begin{array}{c}7(3) \\
7[1-10]\end{array}$ & $<0.001$ \\
\hline Discharge in the eye & $\begin{array}{c}1(2) \\
1[0-8]\end{array}$ & $\begin{array}{c}6(3) \\
5[0-10]\end{array}$ & $<0.001$ \\
\hline $\begin{array}{l}\text { Swelling around the } \\
\text { eye }\end{array}$ & $\begin{array}{c}1(2) \\
0[0-8]\end{array}$ & $\begin{array}{c}4(4) \\
3[0-10]\end{array}$ & 0.001 \\
\hline Pain around the eye & $\begin{array}{c}1(1) \\
0[0-7]\end{array}$ & $\begin{array}{c}3(3) \\
2[0-9]\end{array}$ & $<0.001$ \\
\hline $\begin{array}{l}\text { Change in visual } \\
\text { acuity }\end{array}$ & $\begin{array}{c}1(2) \\
0[0-9]\end{array}$ & $\begin{array}{c}5(3) \\
5[0-10]\end{array}$ & $<0.001$ \\
\hline Nose blockage & $\begin{array}{c}2(2) \\
2[0-7]\end{array}$ & $\begin{array}{c}2(3) \\
1[0-8]\end{array}$ & 0.76 \\
\hline Nasal cavity discharge & $\begin{array}{c}2(2) \\
2[0-8]\end{array}$ & $\begin{array}{c}4(4) \\
3[0-10]\end{array}$ & 0.026 \\
\hline Total score $(0-70)$ & $\begin{array}{c}10(9) \\
8[0-37]\end{array}$ & $\begin{array}{c}30(14) \\
26[8-56]\end{array}$ & $<0.001$ \\
\hline
\end{tabular}

in visual acuity $(\mathrm{OR}=9.5, \mathrm{RR}=4.7, \mathrm{UI}=0.22)$, nose blockage (OR $=0.80, \mathrm{RR}=0.83, \mathrm{UI}=-0.005)$, and nasal cavity discharge $(\mathrm{OR}=$ $3.6, \mathrm{RR}=2.6, \mathrm{UI}=0.13$ ).

In this study population, the total success rate of EN-DCR was
$79 \%$ (68/86 procedures) at a mean of four (SD 2; range 1-8) years after surgery. The success of primary surgeries was $83 \%(53 / 64$ procedures), and that of revisions was $68 \%(15 / 22)(p=0.15)$. There was statistically significantly more scarring in the failures ( $p<0.001$ ), but their endoscopic appearance was otherwise similar to the successes. There were no differences between the primary and revision cases in their symptom scores reported independently or at the visit ( $p=0.91$ and $p=0.37$, respectively).

\section{Discussion}

NLDO-SS is a valid disease-specific instrument for assessing outcomes of EN-DCR. In our experience, it is also clinically useful for preoperative evaluation and for measuring any changes in signs and symptoms during the follow-up. The questionnaire may also be suitable for general practitioners to identify patients who should be referred for a specialist consultation.

Recently, another DCRs symptom questionnaire, Lac-Q score, was presented ${ }^{(13)}$. Lac-Q appears to be a promising tool for use in patient-reported outcome measures. As with the NLDO-SS, Lac-Q also takes into account the severity of the measured items. The most important difference between these two questionnaires is that the NLDO-SS measures only the symptoms related to the lacrimal pathway obstruction, whereas the Lac- $Q$ includes an additional score for social impact. Moreover, there are no questions on nasal symptoms in the Lac-Q; thus, the NLDO-SS could provide useful benefits for patients who underwent surgery with an endonasal approach. One of the most important issues in validating questionnaires is an appropriate sample of patients. In our series, we had 76 patients, and in the validation process of the Lac- $Q$, there were 29 patients in total. It would be interesting to test the concurrent validity of NLDO-SS 
Table 4. Scores of the Nasolacrimal Duct Obstruction Symptom Scores (NLDO-SS) questionnaire filled in at home and at the visit, on an 11-point Numeric Rating Scale ( $0=$ no symptom, $10=$ worst imaginable symptom) and the correlations of two times given answers. Data are mean (SD) and median [minimum-maximum].

\begin{tabular}{|c|c|c|c|c|}
\hline Variable & $\begin{array}{l}\text { Indepen- } \\
\text { dently } \\
\text { reported } \\
\mathbf{n}=\mathbf{8 3}\end{array}$ & $\begin{array}{c}\text { Reported } \\
\text { at the } \\
\text { visit } \\
\mathbf{n = 8 6}\end{array}$ & $\begin{array}{c}\text { Test- } \\
\text { retest } \\
\text { reliability } \\
\text { Spearm }\end{array}$ & $\begin{array}{l}\text { Internal } \\
\text { consis- } \\
\text { tency } \\
\text { an's rho }\end{array}$ \\
\hline Tearing & $\begin{array}{c}3(3) \\
2[0-10]\end{array}$ & $\begin{array}{c}3(3) \\
2[0-10]\end{array}$ & 0.884 & 0.818 \\
\hline Discharge in the eye & $\begin{array}{c}2(3) \\
1[0-10]\end{array}$ & $\begin{array}{c}2(3) \\
1[0-10]\end{array}$ & 0.940 & 0.786 \\
\hline $\begin{array}{l}\text { Swelling around the } \\
\text { eye }\end{array}$ & $\begin{array}{c}2(2) \\
0[0-10]\end{array}$ & $\begin{array}{c}1(2) \\
0[0-10]\end{array}$ & 0.924 & 0.641 \\
\hline Pain around the eye & $\begin{array}{c}1(2) \\
0[0-9]\end{array}$ & $\begin{array}{c}1(2) \\
0[0-10]\end{array}$ & 0.777 & 0.647 \\
\hline $\begin{array}{l}\text { Change in visual } \\
\text { acuity }\end{array}$ & $\begin{array}{c}2(3) \\
1[0-10]\end{array}$ & $\begin{array}{c}2(2) \\
0[0-10]\end{array}$ & 0.758 & 0.756 \\
\hline Nose blockage & $\begin{array}{c}2(2) \\
1[0-8]\end{array}$ & $\begin{array}{c}2(2) \\
1[0-8]\end{array}$ & 0.853 & 0.495 \\
\hline Nasal cavity discharge & $\begin{array}{c}3(3) \\
2[0-10]\end{array}$ & $\begin{array}{c}2(2) \\
{[0-10]}\end{array}$ & 0.825 & 0.701 \\
\hline Total score (0-70) & $\begin{array}{c}14(13) \\
10[0-56]\end{array}$ & $\begin{array}{l}13(12) \\
9[0-56]\end{array}$ & 0.867 & \\
\hline
\end{tabular}

and Lac-Q in a future trial.

\section{Study limitations}

First, questionnaires have their limitations. EN-DCR is most often performed on elderly patients in good general health. However, the elderly may have declining cognitive functions or even dementia, which complicates the use of any questionnaire. This caveat should be kept in mind, and the method (visit or postal questionnaire) for post-operative follow-up should always be assessed on an individual basis. However, this current survey appeared easy and quick to complete. Second, the outcome evaluation of patency to syringing indicates anatomical but not necessarily functional patency, i.e., a natural flow of the tear fluid and so the results presented may be distorted due to the pressure involved in the irrigation procedure. In further studies, functional fluorescein dye-tests should be used as one of the outcome criteria. Third, the sample size was relatively small. Future studies are required, and NLDO-SS should also be tested in subjects with no history of lacrimal surgery.

In this study, the overall success rate of EN-DCR at a mean follow-up of four years was $79 \%$, which is consistent with other reports of long-term follow-ups ${ }^{(5-7,14-16)}$. The success rate of our prospective study population shows a notable decline compared with the primary operation (93\%) and at six months postoperation ${ }^{(3)}$. The main reason for this failure is the excessive formation of fibrosis and scars during the healing process around the rhinostoma ${ }^{(11,17)}$ Several factors, such as infections, anatomical abnormalities, earlier operations and biological factors, may predispose the individual to this postoperative scarring ${ }^{(12,18,19)}$. This finding highlights the importance of long-term follow-up in determining outcomes of EN-DCR.

However, for most patients, long-term follow-up visits beyond one-year after EN-DCR may be considered unnecessary and inconvenient, particularly because the vast majority of the patients are elderly. A practical and cost-effective solution for the patients and the health care system could be the use of a questionnaire. After completing the symptom questionnaire at home, symptomatic patients only could be invited for an additional visit. Thus far, there have been no disease-specific, generally accepted measures for assessing outcomes after EN-DCR in adults.

\section{Follow-up algorithm with NLDO-SS}

Based on the NLDO-SS, we have created an algorithm for followup after EN-DCR to replace the scheduled one-year follow-up for all patients who are capable of reliably completing the questionnaire. When symptom scores are $\leq 10 / 70$, it is unlikely that there is an obstruction (in this study, only 1 patient out of 18 was misdiagnosed); therefore, there is no need for clinical examination. When scores are 11-20/70, a phone call is made to check the answers, and the original answers are confirmed. For these patients, a new questionnaire is sent after 3 months, and if the symptoms remain, a clinical examination should be conducted. If the scores are $\geq 21$, the patients are invited for an additional visit, because it is likely that the patient has an anatomical or functional obstruction. Using this algorithm, the requirement for follow-up visits would decrease markedly. Because of the high negative predictive value (95\%) of the NLDO-SS, there are very few false negatives. Because those patients are asymptomatic, there is no need for a revision surgery. Moreover, false positives will show some postoperative problems that need to be addressed, and therefore, an additional visit is beneficial. Because the quality of life is the mainstay in assessing the overall outcomes, we recommend combining the NLDO-SS with GBI.

The NLDO-SS is a valid clinical tool for assessing outcomes after EN-DCR. There was a notable decrease in the success rate of ENDCR at long-term follow-up.

\section{Acknowledgement}

This study was not financially supported from external sources. 


\section{Authorship contribution}

EP: study planning, clinical examination, analysis and interpretation of data, manuscript writing

GS: study planning, clinical examination, manuscript writing

JS: study planning, clinical examination, manuscript writing HT: study planning, clinical examination, manuscript writing
HK: study planning, analysis and interpretation of data, manuscript writing

\section{Conflict of interest}

None to declare.

\section{References}

1. Woog JJ. The incidence of symptomatic acquired lacrimal outflow obstruction among residents of Olmsted County, Minnesota, 1976-2000 (an American Ophthalmological Society thesis). Trans Am Ophthalmol Soc. 2007; 105: 649-666.

2. Robinson K, Gatehouse S, Browning GG Measuring patient benefit from otorhinolaryngological surgery and therapy. Ann Otol Rhinol Laryngol. 1996; 105: 415-422.

3. Smirnov $G$, Tuomilehto $H$, Kokki $H$, Kemppainen T, Kiviniemi V, Nuutinen J. Symptom score questionnaire for nasolacrimal duct obstruction in adults - a novel tool to assess the outcome after endoscopic dacryocystorhinostomy. Rhinology. 2010 48: 446-451.

4. Leong SC, Macewen CJ, White PS. A systematic review of outcomes after dacryocystorhinostomy in adults. Am J Rhinol Allergy. 2010; 24: 81-90.

5. Dietrich $C$, Mewes $T$, Kuhnemund $M$, Hashemi B, Mann WJ, Amedee RG. Longterm follow-up of patients with microscopic endonasal dacryocystorhinostomy. Am J Rhinol. 2003; 17: 57-61.

6. Onerci M, Orhan M, Ogretmenoglu O, Irkec M. Long-term results and reasons for failure of intranasal endoscopic dacryocystorhinostomy. Acta Otolaryngol. 2000; 120: 319-322.

7. Cokkeser Y, Evereklioglu C, Tercan M, Hepsen IF. Hammer-chisel technique in endoscopic dacryocystorhinostomy. Ann
Otol Rhinol Laryngol. 2003; 112: 444-449.

8. Smirnov G, Tuomilehto $H$, Terasvirta M Nuutinen J, Seppa J. Silicone tubing after endoscopic dacryocystorhinostomy: is it necessary? Am J Rhinol. 2006; 20: 600-602

9. Lund VJ, Mackay IS. Staging in rhinosinusitus. Rhinology. 1993; 31: 183-184.

10. Onerci M. Dacryocystorhinostomy Diagnosis and treatment of nasolacrimal canal obstructions. Rhinology. 2002; 40 49-65.

11. Allen KM, Berlin AJ, Levine HL. Intranasa endoscopic analysis of dacrocystorhinostomy failure. Ophthal Plast Reconstr Surg. 1988; 4: 143-145.

12. Orcutt JC, Hillel A, Weymuller EA,Jr Endoscopic repair of failed dacryocystorhinostomy. Ophthal Plast Reconstr Surg. 1990 6: 197-202.

13. Mistry N, Rockley TJ, Reynolds T, Hopkins C Development and validation of a symptom questionnaire for recording outcomes in adult lacrimal surgery. Rhinology. 2011; 49: 538-545.

14. Muscatello L, Giudice M, Spriano G, Tondini L. Endoscopic dacryocystorhinostomy: personal experience. Acta Otorhinolaryngol Ital. 2005; 25: 209-213.

15. Yuen KS, Lam LY, Tse MW, Chan DD, Wong BW, Chan WM. Modified endoscopic dacryocystorhinostomy with posterior lacrimal sac flap for nasolacrimal duct obstruction. Hong Kong Med J. 2004; 10: 394-400.

16. Zenk J, Karatzanis AD, Psychogios G, Franzke K, Koch M, Hornung J, et al. Long-term results of endonasal dacryocystorhinostomy. Eur Arch Otorhinolaryngol. 2009; 266: 1733-1738.

17. Jokinen K, Karja J. Endonasal dacryocystorhinostomy. Arch Otolaryngol. 1974; 100: 41-44.

18. Goldberg RA. Endonasal dacryocystorhinostomy: is it really less successful? Arch Ophthalmol. 2004; 122: 108-110.

19. Smirnov G, Pirinen R, Tuomilehto H, Seppa J, Terasvirta M, Uusitalo H, et al. Strong expression of HSP47 in metaplastic nasal mucosa may predict a poor outcome after primary endoscopic dacryocystorhinostomy: a prospective study. Acta Ophthalmol. 2011; 89: e132-e136.

Elina Penttilä, MD

Department of Otorhinolaryngology

Kuopio University Hospital

P.O. Box 1777

FI-70211 Kuopio

Finland

Phone: +358-17-175 021

Fax: +358-17-172 509

E-mail elina.penttila@kuh.fi 